\title{
Have Lessons Been Learned? Applications From Ebola to Zika Virus
}

Rita V. Burke, PhD, MPH

$\mathrm{O}$ nly 2 years have passed since the United States was faced with the Ebola outbreak in West Africa. While images from the Ebola response effort are still fresh in the public's mind, we are now faced with our newest infectious disease challenge: Zika virus. As with any large public health disaster event, a host of "lessons learned" articles were published in scientific and medical peer-reviewed journals. The key question is, What did we learn from the recent Ebola virus outbreak and have we been able to apply these lessons to the immediate public health response to Zika virus?

Although there were many lessons learned from Ebola, 2 of the main ones include the importance of risk communication and the utility of social media in public health emergencies. Effective and accurate communication are critical during public health emergencies as was witnessed during the Ebola virus outbreak. The choice of one term (outbreak) over another (epidemic) can considerably influence the perception of the risk of disease. ${ }^{1}$ The recent call for quarantine in the wake of Zika by some policy-makers, as described in this issue of the journal by Dr. Koenig, ${ }^{2}$ suggests that misinformation about Zika virus persists.

The second lesson during Ebola was the emergence of social media as both a tool for communication and a tool for surveillance. Sites such as Twitter, Facebook, and YouTube proved instrumental in the the public's knowledge and understanding of the disease as well as the public's concern. ${ }^{3}$ Social media sites such as YouTube, which has one one billion unique users monthly and has significant potential for enhancing education, was highly underutilized by public health officials. ${ }^{4}$ The emergence of Zika virus has provided an opportunity to fully utilize these channels of communication to reach a wider demographic and to gain insight about people's questions and misinformation.

Zika virus poses a challenge that was absent during the Ebola virus outbreak, thereby making the application of the lessons learned more difficult. The most striking difference is that clinical and public health knowledge about Zika virus continues to emerge rapidly. In contrast, our understanding of the symptoms, transmission, and treatment of Ebola was more developed. The knowledge gap certainly makes communication and use of social media more challenging with Zika virus. Nevertheless, additional infectious diseases, some that we may know even less about than we do Zika virus, will certainly emerge in the near future. We will need to be prepared for and respond to them as well.

Rita V. Burke, PhD, MPH

Children's Hospital Los Angeles

Los Angeles, California

riburke@chla.usc.edu

\section{REFERENCES}

1. Gesser-Edelsburg A, Shir-Raz Y, Bar-Lev OS, et al. Outbreak or epidemic? How Obama's language choice transformed the Ebola outbreak into an epidemic. Disaster Med Public Health Prep. 2016;10(4):669-673. http://dx. doi.org/10.1017/dmp.2016.48.

2. Koenig KL. Quarantine for Zika virus? Where is the science [published online April 1, 2016]? Disaster Med Public Health Prep. 2016:1-3. http://dx.doi.org/10.1017/dmp.2016.56.

3. Rodriguez-Morales AJ, Castaneda-Hernandez DM, McGregor A. What makes people talk about Ebola on social media? A retrospective analysis of Twitter use. Travel Med Infect Dis. 2015;13(1):100-101. http://dx.doi.org/ 10.1016/j.tmaid.2014.11.004.

4. Basch CH, Basch CE, Ruggles KV, et al. Coverage of the Ebola virus disease epidemic on YouTube. Disaster Med Public Health Prep. 2015;9(5):531-535. http://dx.doi.org/10.1017/dmp.2015.77. 